\title{
AS PAISAGENS DA MEMÓRIA DO BAIRRO HARMONIA, EM CANOAS/RS \\ UM ESTUDO A PARTIR DE REGISTROS FOTOGRÁFICOS E RELATOS ORAIS
}

\author{
Francisco de Paula Brizolara de Freitas ${ }^{1}$ \\ Lucas Graeff ${ }^{2}$
}

\section{Introdução}

As histórias de um bairro e de uma cidade podem ser elaboradas a partir de várias fontes - documentos e fotografias oficiais, relatos e imagens produzidas por viajantes, pesquisas etnográficas e arquivos de polícia, por exemplo. No estudo que realizamos junto ao bairro Harmonia, em Canoas/RS, entre os meses de agosto e outubro de 2010, optamos por abordar os relatos orais de seis antigos moradores do bairro em cruzamento com uma pequena coleção de fotografias realizadas durante a pesquisa ou recuperadas de arquivos históricos e familiares $^{3}$. Nosso objetivo era, por um lado, descobrir como esses moradores pensam o passado, o presente e o futuro do bairro Harmonia e sua inscrição na cidade de Canoas. Por outro lado, queríamos articular algumas noções de História Ambiental (Worster, 1991) com os conceitos de memória coletiva (Halbwachs, 2006), lugares da memória (Nora, 1993; Le Goff, 1992) e poética do espaço (Bachelard, 2000). Ao final da pesquisa, os dados recolhidos configuraram aquilo que denominamos "paisagens da memória", ou seja, imagens de lugares e momentos que são investidos de afeto e emoção (Nora, 1993), mas sobretudo que se apresentam como marcos a partir dos quais as memórias individual e coletiva se encontram, permitindo a cada grupo de redefinir sua identidade e revitalizar seus próprios percursos históricos.

O presente artigo visa apresentar duas dessas paisagens afetivas e memoriais. A primeira, intitulada "um passado de pedras e águas", é responsável pela íntima relação entre os primórdios do bairro e a infância dos entrevistados. Nessa paisagem, as transformações da

\footnotetext{
${ }^{1}$ Licenciado em História pelo Centro Universitário Unilasalle (Canoas/RS).

2 Doutor em Antropologia pela Universidade de Paris 5 - Sorbonne. Professor do curso de mestrado profissional em Memória Social e Bens Culturais do Centro Universitário Unilasalle (Canoas/RS). Contato: lucas.graeff@unilasalle.edu.br

${ }^{3}$ As entrevistas com os moradores do Bairro Harmonia e da Vila Cerne aplicadas nesta pesquisa ocorreram no período que compreende os meses de agosto, setembro e outubro de 2010. Todos os moradores foram entrevistados em suas respectivas residências ou locais de trabalho, procurando-se assim obter a melhor condição de conforto físico e emocional do entrevistado, evitando-se possíveis situações de inibição e/ou desconforto.
} 
infraestrutura do bairro, que promovem uma ruptura com o seu passado "rústico, são as mesmas que contribuem a condensar as imagens de uma infância perdida e que consolam as sensações de nostalgia.

A segunda paisagem que trataremos aqui, denominada "A vida comunitária: uma ponte entre o passado e o futuro", se impõe como uma articulação necessária entre as vidas coletivas de "ontem" e de "hoje". Ancoradas em edificações religiosas e centros comunitários, as relações de sociabilidade contribuem a "presentificar" a história e a memória do bairro. Nesse sentido, tais edificações e espaços comunitários se apresentam como marcos onde se cruzam diferentes "correntes da memória coletiva" (Halbwachs, 2006), construindo assim uma "ponte" pela qual transcorrem passado, o presente e o futuro.

\section{Um passado de pedras e águas}

Se, como propõem Cornelia Eckert e Ana Luiza Carvalho da Rocha, "a Cidade é um território expressivo da experiência temporal contemporânea dos grupos sociais que nela habitam" (Eckert e Rocha, 2001, p. 5), um estudo das paisagens da memória de um bairro como o Harmonia, em Canoas/RS, deve permitir a recomposição das experiências sociais dos grupos urbanos que ali habitam. Com efeito, a partir das entrevistas que realizamos e das fotografias que recuperamos junto a antigos moradores do bairro, a primeira paisagem que vem à tona é de um espaço poético onde se refugiam experiências de um passado pensado a partir do presente. Mais precisamente, nós encontramos nesses depoimentos as imagens de um lugar cujas origens estão marcadas por aquilo que Worster (1991) denomina "aspectos orgânicos e inorgânicos da natureza", no caso a terra, as pedras, as águas e o carvão:

\footnotetext{
“Aqui era só carvão! [...] Era um bairro de carvão aquela coisa toda, tudo mato de eucaliptos, aquela coisa toda. Chão tipo carvão era preto a terra. Depois com o tempo a gente achava maravilhoso eles colocarem aquelas pedras, a gente machucava os pés e depois eles começaram a fazer o calçamento da rua. A vila começou a crescer muito. A vila era muito pobre mesmo e com o tempo foi crescendo. Quando nós viemos para cá com meu pai nós éramos em 11 filhos e a vila era isso aí, era carvão, era preta a terra. A gente via cavalos, carroças, mas era bom!" (Irene Mancy, moradora da Vila Cerne, empresária, 63 anos, entrevistada em 2010).

"A rua era pedregulho, as pedras e o valão na frente das casas e sem água. Água só do poço [...] A rua era rebaixada e carro não entrava [...] A nossa rua aqui era barro e valo também então fizemos abaixo assinado para botar pedra aqui! Pra melhorar botaram aquela baita pedra”. (Teodoro Ivankio, morador do Harmonia, aposentado , 89 anos ,entrevistado em 2010).
} 
"Bairro de carvão", "ruas de pedregulho", "valões", "casas sem água". Como diria Gaston Bachelard, a função do espaço é "manter o tempo comprimido" (Bachelard, 2000, p. 28). Daí porque essa paisagem rústica se confunde com experiências de infância romantizadas e desaparece com o processo acelerado de urbanização responsável pela domesticação do espaço e, por conseqüência, das lembranças:

\footnotetext{
"Mas primeiramente eu lembro que a rua era feita de pedra e fazia um pó tremendo e eu lembro brincando ali na minha infância, jogando bola, jogando taco e brincadeiras que a gente não vê mais hoje, brincar de esconde-esconde, polícialadrão, era prego no pé, dedo ralado, era uma época bem legal!" (Sidiclei Mancy, morador da Vila Cerne, funcionário público, 37 anos, entrevistado em 2010).

"O que eu me lembro do bairro de quando era pequeno são poucas coisas, como algumas ruas não eram asfaltadas, tinha um valão na Rua José Veríssimo onde hoje são as calçadas das casas". (Fagner Dornelles de Souza, morador do Harmonia ,professor , 24 anos, entrevistado em 2010.)
}

Inscritas num tempo comprimido, as brincadeiras nas ruas de pedra são um marco memorial que indicam uma ruptura significativa entre o passado e o presente. Porém, se "é no plano do devaneio, e não no plano dos fatos, que a infância permanece em nós viva e poeticamente útil”, como escreveu Gaston Bachelard (2000, p. 35), então a ruptura é muito mais fatual que afetiva. A paisagem "perdida" de um passado rústico (rural, renitente ao moderno) preserva a poesia da infância e consola a sensação de nostalgia. Se lá onde se encontram as pedras e o carvão reside à infância, o retorno a essa paisagem perdida através dos "jogos de memória" (Eckert e Rocha, 2000) se impõe como uma espécie de instante poético a partir do qual a experiência de duração pode recomeçar.

Nesse sentido, há imagens e paisagens do passado que fazem a ponte com o presente e instauram "intuições do instante" (Bachelard, 1992; Graeff, 2011). Tais imagens, tão ricas de significado quando àquelas ligadas a terra e à rusticidade, indicam transformações consideradas positivas, tais como a canalização, o acesso ao esgoto e à luz elétrica. As pedras e o carvão desaparecem - e com eles, a infância -, trazendo o "moderno" para o interior do bairro:

\footnotetext{
“A rua não era formada, só passava carroça. Tinha 12 casas na Vila Cerne. Tinha muitos valos, não tinha esgoto, não tinha luz elétrica, não tinha escolas. Era tudo granja de arroz por todos os lados! . Antigamente, nós tínhamos que ir para o centro com as calças pelos joelhos devido ao barro, pois era um lugar muito encharcado. Hoje tá tudo asfaltado. Outra coisa é que naquela o único lazer que se tinha era ir ao Pradinho na Rua José Veríssimo para ver as corridas de carroças.” (Manoel Antonio de Souza, morador do Harmonia, motorista , 54 anos, entrevistado em 2010).
} esgoto, aquelas valas era justamente por causa das enchentes que eu ouvi falar, que 
o pessoal antes de mim falavam". (Sidiclei Mancy, morador da Vila Cerne, funcionário público, 37 anos, entrevistado em 2010).

A “domesticação das águas e das ruas", isto é, a instalação da infraestrutura de água e esgoto do bairro Harmonia e da Vila Cerne, indica as diversas mudanças do bairro desde os tempos dos arrozais, passando pelas ruas de "carvão" e pelas enchentes e a gradativa canalização das águas e dos esgotos.

"Não era um terminal de esgoto, tanto que nós não tínhamos banheiro. Era tudo feito nas patentes como a gente chamava. Então conforme fosse ficando muito cheia ia-se tapando e abrindo outra. Era assim que acontecia. Então até a urbanização, canalizações dessas valas foram construídas, os banheiros e ter o escoamento do esgoto." (Sidiclei Mancy, morador da Vila Cerne, funcionário público, 37 anos, entrevistado em 2010).

Segundo os entrevistados, as condições de infraestrutura tais como calçamento e esgoto eram precários, mas pautavam uma infância feliz. É somente através da lembrança das enchentes de 1941 e de 1976 que a precariedade da infraestrutura se torna dramática. Desde então, todo melhoramento urbano é visto com bons olhos.

\footnotetext{
"Depois vinham as enchentes, até na casa tinha enchente, por três vezes tiveram enchentes! Uma enchente depois a outra." (Teodoro Ivankio, morador do Harmonia, aposentado, 89 anos ,entrevistado em 2010).

"Tinha muitas valas nas frentes das casas, eu lembro muito disso. Inclusive não tinha esgoto. Aquelas valas eram justamente por causa das enchentes que eu ouvi falar, que o pessoal antes de mim falava. Então foram abertas essas valas para escoar a água." (Sidiclei Mancy, morador da Vila Cerne, funcionário público, 37 anos, entrevistado em 2010).
}

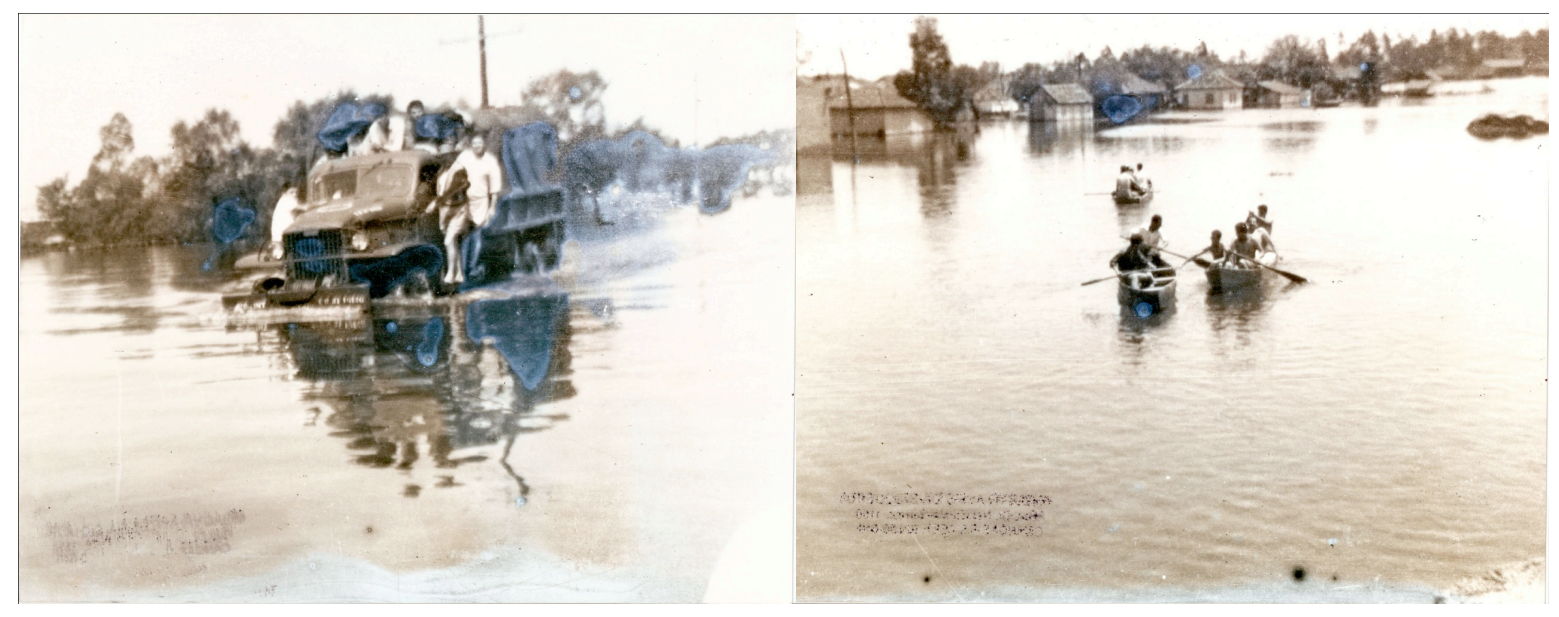

Enchente de 1967 Acervo Moacyr Ayres da Siqueira.
Enchente de 1967

Acervo Moacyr Ayres da Siqueira. 
As enchentes configuram uma paisagem do passado. Hoje existem projetos da prefeitura municipal (Plano Diretor Urbano Ambiental) visando à melhoria e o desenvolvimento de todos estes aspectos que se fazem necessários como o calçamento das ruas e adequação do esgoto. Além disso, algumas obras já estão em andamento no sentido de se melhorar os atuais diques e construir outros mais ao redor da cidade, para a proteção contra as cheias dos rios que banham Canoas (Sinos, Gravataí e Jacuí).

Se as reformas infraestruturais vieram melhorar a qualidade de vida dos moradores do bairro Harmonia, elas também devem ser vislumbradas, do ponto de vista da história ambiental, como uma transformação profunda das paisagens do bairro. Um extraordinário contraste se estabelece entre essas imagens de ruas dominadas pelas águas e as paisagens de infância marcadas por pedras e carvão. É nesse sentido que é possível dizer que a história da comunidade se inscreve num "passado de pedras e águas".

\section{A vida comunitária: uma ponte entre o presente e o passado}

Ruas de pedras e carvão, brincadeiras de infância, enchentes. As paisagens do bairro Harmonia são marcadas por essas imagens e deslocamentos da memória, mas não teriam muito sentido para além da vida cotidiana. De certa forma, é na vida comunitária que a história ambiental se inscreve. Ancorada na vida coletiva e nas relações de sociabilidade que aí se estabelecem, história e memória se "presentificam", construindo assim uma "ponte" fundamental pela qual transcorrem o passado, o presente e o futuro.

Nos ritmos da vida cotidiana, a sociabilidade e a sensação de participar de uma comunidade se transformam. Laços de vizinhança e de compadrio se estabelecem e se rompem. Novos membros se instalam, outros abandonam suas residências e comércios. No final das contas, o que fica é a relação afetiva com as paisagens e lugares da memória. Se as paisagens contam histórias de infância e dos enfrentamentos de cada um com a dura realidade da terra batida e do carvão, os lugares da vida comunitária se impõem como marcos coletivos a partir dos quais a memória social ultrapassa instantes aparentemente pontuais e consolida intervalos de duração. Organizados formalmente e afetivamente pelo pensamento, são esses intervalos que produzem o sentido da experiência comunitária.

No caso dos edifícios religiosos, por exemplo: a relevância da religião na vida das pessoas, o esforço dos moradores para concluir a construção da igreja católica e a vida em 
torno delas, assim como o reconhecimento da comunidade para com os seus idealizadores e construtores, são marcos afetivos que fazem "trabalhar a memória", como diria Paul Ricoeur (2007).

\begin{abstract}
"Eu moro a 50 anos na Rua Eng. Kindler, eu sou fundadora da Vila Cerne. Quando nós viemos para cá meu pai comprou este terreno aqui do lado e depois eu comprei esse aqui.[...] Nós fundamos a igreja católica, formamos um clube de mães e a gente lutou para ter este posto de saúde aqui que é municipalizado.[...] Quando o meu pai fundou a igreja, nós também já tínhamos o campo em frente da igreja, nós fundamos o campo ali. Foi a minha família que fundou quando nós viemos para cá. Formamos uma diretoria, eu fui presidente, meu irmão foi presidente. Então ficava bem na frente da igreja.Então a nossa família fundou tudo! Nós formamos a Vila Cerne! Nós fundamos a Vila Cerne!" (Irene Mancy, moradora da Vila Cerne, empresária, 63 anos, entrevistada em 2010).
\end{abstract}

"E ali na Vila Cerne, que é uma própria vila do bairro Harmonia, vieram uns irmãos maristas, Irmão Sechim e irmã Matilde, ele era secretário do papa João XXIII, ele visitou uma família na intenção de fundar uma igreja que era uma forma diferente da igreja católica, não era essa igreja tradicional que o padre faz o sermão. Era uma igreja que trabalhava com a partilha! Era uma igreja que trabalhava com a língua do povo oprimido! Era essa a idéia, então eles foram lá e um casal indicou a minha avó e outros tios, que são essas famílias que movimentaram o bairro aqui, na época dos anos setenta e oitenta. Reuniram a minha avó, apareceu aquele homem estranho na casa dela, ficaram receosos, que é esse cara que quer se dedicar tanto aos pobres? A missão deles até hoje é voltada para esse fim. Aceitaram. E aí começaram a se reunir na casa dela e eu fui a primeira criança a representar a Pastoral da Criança de Canoas." (Sidiclei Mancy, morador da Vila Cerne, funcionário público, 37 anos, entrevistado em 2010).

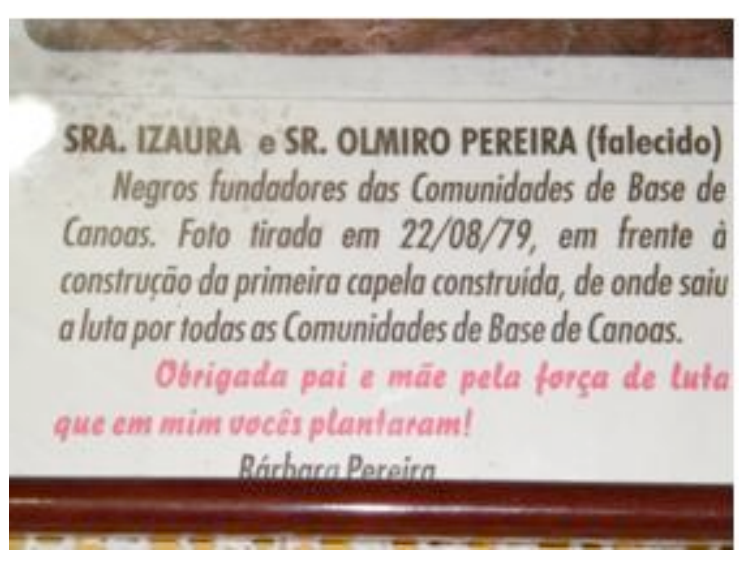

Placa comemorativa, Igreja Católica da Vila Cerne

Acervo da família Mancy

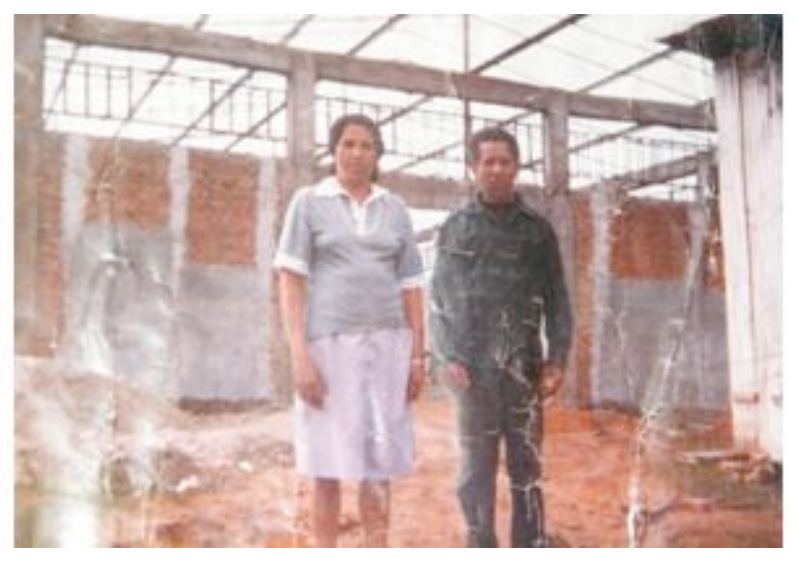

fundadores da Igreja Católica da Vila Cerne Acervo da família Mancy

Sra. Izaura e Sr. Olmiro Pereira, 


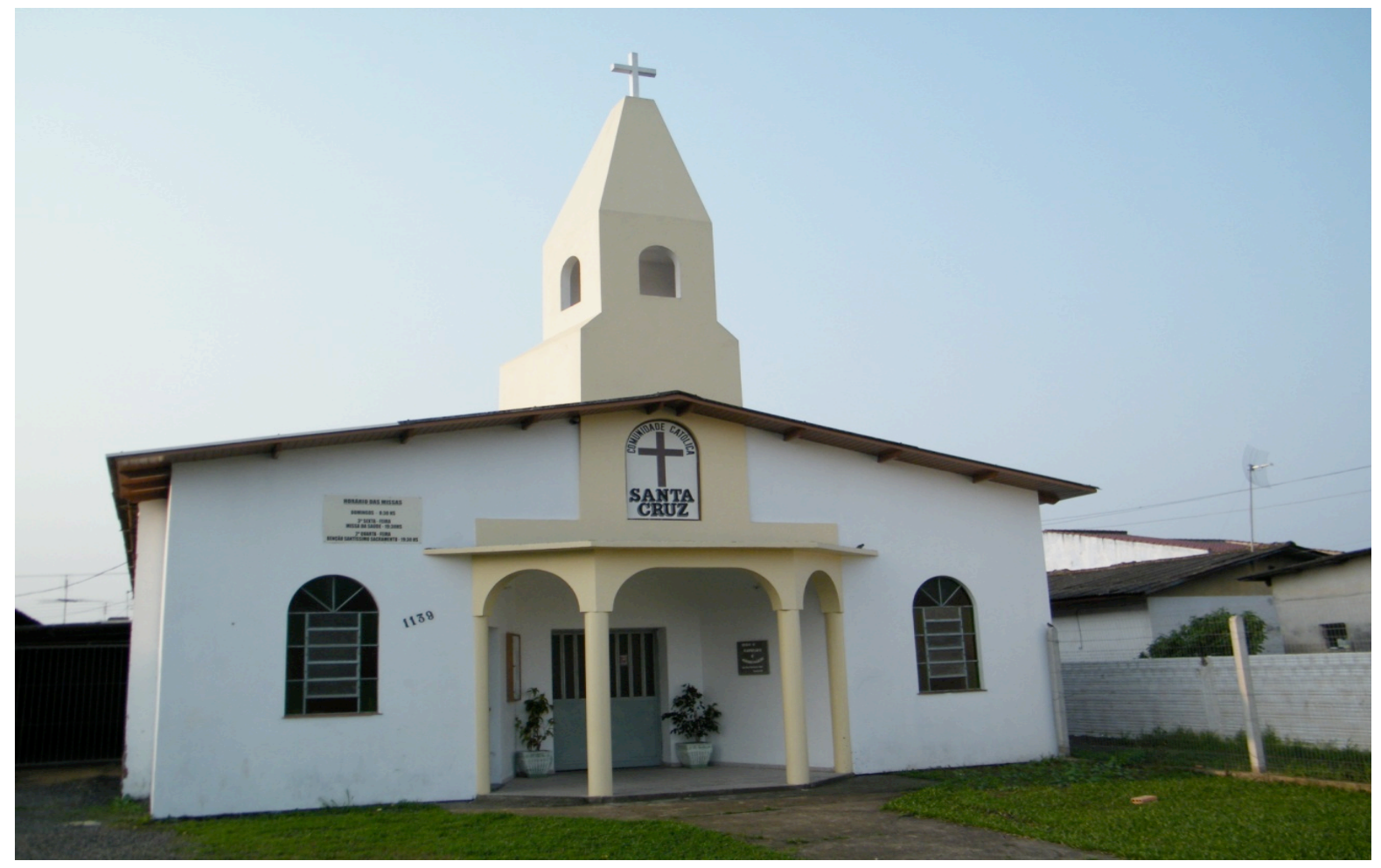

Igreja Católica Vila Cerne.

Foto de Francisco de Paula Brizolara de Freitas

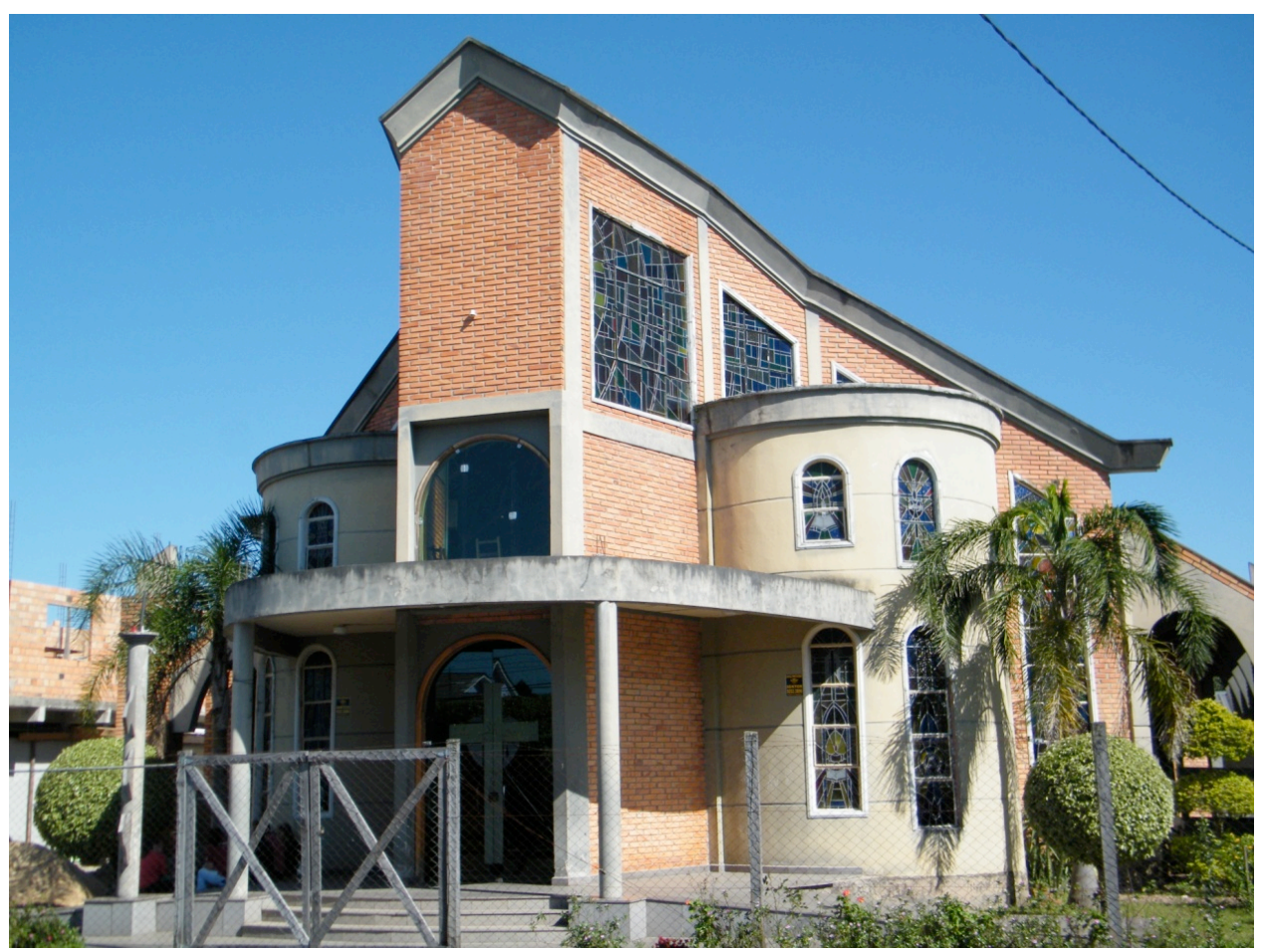

Igreja Sagrado Coração de Jesus

Foto de Francisco de Paula Brizolara de Freitas 
Outro lugar de religiosidade que marca as paisagens do bairro é a Igreja do Sagrado Coração de Jesus. Além de estar localizada no centro do bairro Harmonia (Rua Carlos Gomes) e der ser um ponto de referência importante na comunidade, a igreja é muito freqüentada por todos os moradores, principalmente pelos vários grupos de jovens que executam diversas atividades de caráter filantrópico e de ajuda junto aos necessitados. A igreja possui uma arquitetura moderna e tem como característica principal os "vitrais" localizados nas paredes no térreo, de forma que os mesmos fiquem na altura de observação do devoto, ou seja, ao seu lado, "para o devoto ficar ao lado de Deus".

\footnotetext{
"Abriu-se o terreno para a construção da igreja, se juntamos alguns conhecidos para construir a igreja e começamos a trabalhar ali. Ali era muito selvagem, eu vou te contar, a gente tinha que andar armado ou dar em alguém." (Teodoro Ivankio, morador do Harmonia, aposentado, 89 anos, entrevistado em 2010).

"A Igreja Sagrado Coração de Jesus era uma igreja antiga de madeira, nós saíamos daqui para ir naquelas festas de São João, festas antigas que tínhamos lá, nós íamos lá, quando a gente era guria, moça. Aquela praça é antiga, onde é essa igreja Sagrado Coração Jesus.” (Irene Mancy, moradora da Vila Cerne, empresária, 63 anos, entrevistada em 2010).
}

Para além dos espaços religiosos, a ponte entre o passado e o presente do Bairro Harmonia passa pelos centros comunitários e pela associação de moradores de bairro. Com efeito, a integração e participação da comunidade com o bairro Harmonia estão solidamente embasadas nas ações e atividades dos centros comunitários $1^{\circ}$ de Maio (Rua Carlos Gomes) e o Centro das Comunidades (Rua José Veríssimo) também conhecido como Centro São Francisco.

\footnotetext{
"Foi um bairro que começou a desenvolver com a união dos moradores criando a associação de moradores, time de futebol, a primeira igreja católica das comunidades eclesiais de base, foi fundada também na Rua Eng. Kindler e através dessas entidades foi que se deu a ocupação do bairro Santo Operário." (Sidiclei Mancy, morador da Vila Cerne, funcionário público, 37 anos, entrevistado em 2010).
}

\section{Considerações finais}

No cotidiano e através dos tempos, as paisagens do bairro Harmonia se revelam nas experiências de seus moradores. Neste trabalho, procuramos dar conta dessas experiências. Assim, através de relatos orais e registros fotográficos, um ponto de vista sobre a história do bairro Harmonia e de sua inscrição na cidade de Canoas foi desenvolvido. Não se trata, porém de um ponto de vista exclusivo. Ao contrário: fundada em um conjunto restrito de relatos, a perspectiva aqui trabalhada não pode ser considerada única ou "mais verdadeira" que outra. 
Há diversas maneiras de viver, de habitar e de lembrar um bairro. A força da história ambiental é de dar conta dessas lembranças, inscrevendo-as na vida social em seus diferentes aspectos - orgânicos, inorgânicos, ambientais e éticos.

Em relação aos relatos orais (entrevistas) dos moradores do bairro, importa lembrar que os acervos de fotos são constituídos de imagens que retratam momentos da história, do passado do bairro. Ou seja, momentos fixados na imagem que compreendem primordialmente a evolução e o desenvolvimento do bairro nas quais as famílias lembram algo para reafirmar determinados valores, vínculos, identidade.

Ao mesmo tempo, é preciso pensar as imagens e relatos deste trabalho a partir de um olhar simultaneamente crítico e original. Daí a formulação das paisagens e lugares da memória tratados neste trabalho. Por um lado, partindo das lembranças oferecidas pelos entrevistados em seus relatos orais e dos registros das enchentes de 1941 e 1967, um passado de pedra e de águas se impôs. Nessa paisagem rústica, lembranças de infância se inscreveram, assim como algumas impressões sobre as transformações do bairro. Por outro lado, visando dar conta dessas experiências de moradores, abordamos alguns temas da vida comunitária e os espaços de religiosidade, de associação, de lazer e de jogo se apresentaram como marcos a partir dos quais a memória social estabelece intervalos de duração coletivos. Organizados formalmente e afetivamente pelo pensamento, são esses intervalos que permitem a apropriação afetiva desses "lugares da memória" que permitem a cada grupo de redefinir sua identidade e revitalizar seus próprios percursos históricos.

\section{Referências}

BACHELARD, Gaston. A poética do espaço. São Paulo: Martins fontes, 2000. . L'intuition de l'instant. Paris: Stock, 1992

ECKERT, Cornelia; ROCHA, Ana Luiza. Os jogos da memória. Revista Iluminuras vol. 1, n. 2, 2000, Porto Alegre, PPGAS/UFRGS. Disponível em: http://seer.ufrgs.br/iluminuras/issue/view/767

- Premissas para o estudo da memória coletiva no mundo urbano contemporâneo sob ótica dos itinerários de grupos urbanos e suas formas de sociabilidade. Revista Iluminuras vol. 2, n. 4, 2001, Porto Alegre, PPGAS/UFRGS. Disponível em: http://seer.ufrgs.br/iluminuras/issue/view/769

GRAEFF, Lucas. Quando durar é recomeçar: a narrativa de vida como intuição do presente. Mouseion, Revista Eletrônica do Museu e Arquivo Histórico Lasalle, n. 7, jan-jun 2011.

HALBWACHS, Maurice. A memória coletiva. São Paulo, SP: Centauro, 2006.

LE GOFF, Jaques. História e memória. Campinas, SP: Unicamp, 1992.

NORA, Pierre. Entre história e memória: a problemática dos lugares. São Paulo, SP: PUCSP, 1993.

RICOEUR, Paul. A memória, a história, o esquecimento. Campinas, SP: UNICAMP, 2007. WORSTER, Donald. Para fazer História Ambiental. Estudos Históricos. Rio de Janeiro, v.4, n.8, p. 198-215, jan/jun. 1991. 